\title{
Hegel and the Philosophy of Food*
}

Let me preface my discussion of Hegel's Practical Philosophy with one wholesale concession. At least for present purposes I propose to allow that Hegel's writings in practical philosophy mean exactly what Robert Pippin says they mean. So when Hegel tells me that "identity is absolute negativity because the notion has its complete external objectivity in nature," or that "spirit raises its existence into Thought and thereby into an absolute antithesis, and returns out of this antithesis, in and through the antithesis itself," I shall defer to Pippin to decipher the Hegelian code. ${ }^{1}$ Of course I do not mean to suggest that Pippin's interpretation of Hegel's distinctive idiom is beyond controversy. Nothing could be further from the truth. Pippin's work on Hegel has been intensely controversial for two decades now; indeed it is fair to say that he has sparked an interpretative war in Hegel studies, with battle lines now sharply drawn and no hint of a cease-fire on its way. But I propose to leave that interpretative quarrel to others - partly because I have no stomach for it myself, but mainly because I want here to pursue a different sort of task: assessing the philosophical position that Pippin attributes to Hegel and develops with considerable subtlety in this new book.

In thinking about just what that position is, I find it useful to make use of a device that Pippin himself uses on several occasions: the high-altitude sketch. I see Pippin's Hegel as situated on a field of battle, surrounded by philosophical opponents. Some of the opponents carry banners from one or another source in the history of philosophy, but the positions themselves are all represented by powerful contemporary advocates. This, indeed, has been one of the most striking (and controversial) of Pippin's accomplishments over the past twenty years: against all odds he has managed to make Hegel our philosophical contemporary in current discourses across a wide range of themes and disputes. And he has done so, I might add, almost single-handedly.

So who are the opponents faced by this $21^{\text {st }}$ century Hegel? From my high-altitude vantage, the opponents are too numerous to count, so my survey is anything but exhaustive. For present purposes I shall focus on four. Two of the opposed positions march under the banner of Philosophical Naturalism, although their respective positions share little in common. The first is what I think of as Ancient Naturalism, although it is a position that has been gathering a considerable contemporary following. Ancient Naturalism is a form of normative naturalism -- a thesis about living well. But it is built on a metaphysical foundation: it is committed to a robust form of teleological essentialism about living beings. Understanding what a life form is, according to this view, involves understanding what it is for it to live well. For the normative naturalist, the good for human beings involves living in accord with man's essential nature. To be sure, the Ancients had their differences about what that

\footnotetext{
* Review of Robert Pippin, Hegel's Practical Philosophy: Rational Agency as Ethical Life (Cambridge: Cambridge University Press, 2008), xi+308 pp. Unadorned page references refer to this work.

${ }^{1}$ The first passage is from The Philosophy of Subjective Spirit; the second from the Phenomenology. They are quoted and discussed on p. 45 and p. 234 respectively.
} 
essential nature amounted to, but they were in very broad agreement that one could not live well without being true to it.

If the Ancient Naturalist privileges teleological causation in this normatively substantial way, the Modern Naturalist tends to give privilege to efficient or mechanical causation. For the Modern Naturalist, authoritative explanation comes from the natural sciences. Accordingly, the authoritative explanation of human behaviour (including human action) consists in an account of the distinctive operations of the bio-mechanical entity that a human being is. Modern Naturalism now comes in a thousand flavours; in its most extreme versions, it proposes to dispense with the notion of rational agency altogether - so much jetsam to be abandoned with folk psychology. Less extreme varieties propose one or another reductive account of human action, drawing on the resources of neurophysiology, evolutionary biology, empirical psychology, and so on.

A third hoard of opponents can be grouped together under the heading of Relativism. On this familiar position - much descried but perennially tempting - the wisdom of practical philosophy is, in effect, that there is no such wisdom, or certainly no final wisdom, no such thing as the human good, the just political order or the right organization of man's affairs. There are only so many, infinitely varied, temporally and culturally located norms and virtues.

The final camp of opponents - or at least the final one that I shall concern myself with here comprises the Quietists. The Quietists tend to favour a therapeutic model of philosophical work. But unlike the therapists of the ancient schools, these modern Quietists follow the Wittgensteinian maxim to avoid the construction of philosophical theories, whether of human agency, human freedom, or the human good. Philosophical work, insofar as there is any, consists not in answering the old vexing questions (what is an action?, is there free will?, what is the good?, etc.) but in learning to recognize that such questions are dispensable and perhaps best lost, that our ordinary discourse of human action and practical reasoning stands in no need of support from any distinctively philosophical discourse or theorizing.

It may seem obvious that a Hegelian position stands implacably opposed to all four of these opponents. The Quietists are suspicious of philosophical theorizing; Hegel is surely the patron saint of grand philosophical theory. The Relativists reject above all any claim to Absolute Knowledge; yet this is exactly what Hegel seems to claim as his crowning achievement. Modern Naturalists see empirical natural science as the privileged form of knowledge; for Hegel that privilege belongs to philosophy as speculative thinking. The case of the Ancient Naturalists may be the most complex. Hegel consistently professes a deep regard for the Ancients, but he always tempers his praise with the thought that the Greek synthesis was somehow one-sided, incomplete, unstable. Moreover, the central lacuna Hegel alleges in Ancient thought is also the centerpiece of Hegel's Practical Philosophy: the idea, and the ideal, of human freedom.

So how does Pippin's Hegel engage these opponents? His approach is surprisingly concessive. Start with the Modern Naturalists. Diehard opponents of modern scientific naturalism typically insist that natural scientific explanation can never capture the characteristic features of human 
consciousness, human cognition, human intentionality generally. Yet Pippin allows that neurological descriptions of cognition and evolutionary-biological descriptions of ethical dispositions are "undeniably possible" (48). What does Pippin's Hegel say to his Relativist opponents? Well, he says a lot. But one insistent theme runs like this: “there is nothing left to 'counting as a rational norm' than being taken to be one, effectively circulating as one in a society, acquiring the authority that is determinative for what happens ..." (198). Relativists may be surprised to find themselves with a Hegelian ally! What about the Quietists? Surely Hegel is the consummate Noisy philosopher, who recognizes a deep and fundamental place for generalizing philosophical theory in the well-functioning human society. That may be, but Pippin's Hegel manages to find quite a lot of common ground with the Quietists as well. “[T]he ethical world is alright by itself, and requires no instruction or philosophical justification. ... [C]onsiderations adduced in philosophy ... are not and could not be practical reasons" (268). The case of Ancient Naturalism is once again the most complex; indeed I would like to suggest that perhaps Pippin's Hegel needs more from Ancient Naturalism that he allows. But once again we find a significant concessive note in Pippin's account of Hegel's relation to the Ancients; indeed it is in Aristotle that Pippin finds one of Hegel's closest philosophical brethren.

But of course all this concession is just part of the story - a characteristically Hegelian part, I suppose, insofar as the Hegelian schtick always includes the pretense of incorporating one's philosophical opponents. So the tone of concession is always balanced by a corresponding assault. Natural scientific accounts of action may be possible, but they can never be complete and are never fully satisfying. There may be a truth in Relativism, but that very fact points to one of its principled limits. The Quietists may be right that ordinary practical reasoning is (or at least can be) perfectly selfsufficient, but there is nonetheless an extra-ordinary philosophical discourse which teaches us something about the circumstances under which such self-sufficiency has become possible. As to the Ancients with their fixed teleological essentialism, Pippin's Hegel's has one master-blow to deal against them: for us no merely given essence - nothing handed down from God or Reason or Nature as such - can ever suffice to settle the question that is raised when one asks about the reasons for action.

Enough of the high altitude work. We need to think about how this will play out in practice. So I suggest that we turn our attention to the ultimately nitty gritty practical matter: What's for dinner? What, if anything, could or should a Hegelian say about food and eating? Notice, first of all, the ways in which our large scale battle will play out with regard to this small scale problem. The Modern Naturalist can offer us a fine-grained scientific account of digestion and nutrition, the neuro-chemistry of appetite, the hygiene of food preparation. The Ancient Naturalists will give us their characteristic advice: eat what is fitting for you, given the essence that characterizes your kind. (They will then characteristically go on to quarrel over what that essence is, and whether food should accordingly be raw or cooked, whether we should be vegetarians, etc.) The Relativist will tell us, in effect, "to each his own." This is just one of those matters over which individuals and cultures vary - what is disgusting to me is a delicacy to you, and it is just a mistake to think that there is some fact of the matter to be settled here. And the Quietists will insist that there is really no scope for any 
philosophical account of these matters. Everything there is to be known about food is known by the cooks and the agri-scientists and the nutritionists and the maîtres $d \ldots$. Philosophy has nothing to contribute. So where on this map might we locate a Hegelian practical philosophy of food?

In thinking about this question, it may help to start with the dining habits of the Australian Koala (Phascolarctos cinereus). Think, for a moment, about a koala, setting about its dinner. A mature koala, as it happens, will sleep as much as twenty hours a day. Presumably one of the reasons it wakes up is that it occasionally finds itself hungry. But even this is probably to over-describe koala experience. It does not find itself hungry. It wakes up because it is hungry. It wakes up with an appetite. And what happens then? Well, koalas only eat one thing: the leaves of eucalyptus trees. And since they are tree-dwelling creatures who live in the eucalyptus forest, there is generally plenty of dinner about to be found. In short, koala dining is a paragon of dietary immediacy. Koalas never think about where to have dinner or what to order. Their dietary habits are utterly governed - and perfectly governed - by immediate instinct. Or, to use a word Pippin's Hegel doesn't like much, they are governed by conscience. Koalas are endowed with an instinctive, normatively rich sense for what is good for them in dietary matters. And they are so constructed that all and only that which is good to eat presents itself to them as food. As the Stoics said, they live well by following nature.

But if koala dining is immediate, matters stand very differently with human dining. There is a superficial similarity, of course. We human beings get hungry, we find ourselves instinctively drawn to nourishment, we eat to satisfy our hunger. But here the similarity ends. If koala dining was immediate, human eating is saturated with mediation. For starters, we are omnivores. Koalas can only really eat one thing; human beings can eat more-or-less anything. So we must choose. The perfectly natural, animal function of eating must, for man, be mediated by some sort of mechanism for decision. And because of this we need all sorts of cognitive equipment to sustain this decision: memory to recall what was good (or not) to eat; some medium of cultural transmission to pass this information on to our kin, etc. It is worth recalling that one of the oldest functions of ancient religions was to provide dietary guidance. And of course all of this is further complicated by the fact that we cook and farm - and have others cook and farm on our behalf. As part of this whole package of mediation, we human beings come to have a relation to our appetites that is utterly unlike that enjoyed by koalas. ${ }^{2}$ Here is Pippin's Hegelian formulation:

Hegel's position is that some ... sentient creatures do not merely embody their natures, in the way a stone or planet or an insect might be said simply to be what it is. Some come to be in some sort of mediated and self-directed relation to their immediately felt or experienced dispositions, sensations, and inclinations. (51)

So for we human beings an appetite does not immediately move us to eat. It occurs in that loosened space between instinct and motion that Rousseau identified as the native soil of human freedom.

But looseness of instinct is not enough to make freedom - not for Rousseau and certainly not for Pippin's Hegel. The crucial question is about what comes to occupy that loosened space. What

\footnotetext{
${ }^{2}$ On the theme of koala eating, and its contrast to ours, I have borrowed freely from Michael Pollan, Omnivore's Dilemma (New York: Penguin Press, 2006).
} 
kind of answer can suffice for the question, once posed, "what ought I to eat"? For this act of questioning is something quite different in kind from hunger, or the experience of hunger. It is an invitation to reflection and deliberation, and it is far from clear what counts as a satisfying answer. Should I eat what is closest at hand? What is healthy (according to whom and by what standard)? Is it ethical to eat meat? Should I buy local? Eat kosher? What about the ecological and economic practices that I indirectly sustain when I shop at the dominant supermarket? Now Pippin's Hegel is not much interested in these first order ethical questions; indeed there is virtually no substantive guidance for action in this book of Practical Philosophy. Ultimately his concern is rather with the form of such questioning as such, and with the problems of freedom that are introduced once this particular barn door is opened.

Before addressing these matters, however, it is worth pausing to keep score. Notice first the structure of the story we have just been telling. In Hegelian terms it is a story about the relation between Nature and Spirit [Geist]. The person who asks what she should eat is a geistig entity. This is not to say that she is composed of some immaterial substance, nor is it to deny that she is also part of the natural world. Eating is, after all, a consummately natural function. But at some point in the continuum of natural being, or in the historical evolution of natural forms, a change is introduced. Here is how Pippin describes it:

The suggestion Hegel appears to be making is simply that at a certain level of complexity and organization, natural organisms come to be occupied with themselves and eventually to understand themselves in ways no longer explicable within the boundaries of nature or in any way the result of empirical observation. (46)

This development brings with it the need for a different kind of explanation. Once simply cannot explain human dietary practices (whether in general or in some particular case) in anything like the way one can explain the feeding behaviour of a koala.

We can also now begin to see the texture of Pippin's differences with his two Naturalist opponents. A rich and complex bio-physiological account of nutrition may be a perfectly satisfying answer to our all our questions about koala eating. But by itself it simply doesn't fill the gap that opens up in the distinctively mediated forms of dining that characterize the human situation. No amount of physiology will settle the predicament of a modern secular Jew wondering whether to eat pork; neither will it provide the higher-level account that Hegel seeks - an account of the personal, social and cultural forms of deliberation that do speak to that question. But it should also be clear why and how Pippin's Hegel cannot content himself with the position of the Ancient (Normative) Naturalist either. The maxim, as the Stoics put it, to live well by following nature, generates an immediate paradox for anyone in a position to take it seriously. For while it is true that the animals do well by following their nature, anyone who starts to wonder about living well has already, in that very questioning, exhibited a rather distinctive nature - a nature in which following nature involves responding to reasons, and acting (freely) on their basis. So how can I follow nature if my nature is to be free?

The centerpiece of the positive Hegelian position on these matters, at least on Pippin's accounting, lies in a distinctive conception of human action and agency. As a first approximation, the 
Hegelian account of action is organized around an interplay between the inner (or subjective) and the outer (and public) dimensions of agency. In undertaking an action, some subjective state of the agent an intention, a plan, a choice - is made manifest in a public undertaking. Or as Hegel likes to put it, "the content of what is thought takes on the form of being" (cited at 133). But this is only a first, and inadequate approximation. The relation between the inner and the outer dimensions of action turns out to be quite intricate. For on the Hegelian account, the identity of the subjective intention cannot itself be fixed or identified except with reference to the outer manifestation that follows. Suppose that I tell myself privately that I will give up eating meat for Lent, or kick my Diet Coke habit. But perhaps I'm not all that confident about the strength of my resolve, so to avoid humiliation I don't share my secret resolution with anyone else. And sure enough, come that first lunchtime, I find myself placing my usual order for a burger and a soda. Here, the Hegelian will insist, the objective, outer manifestation puts the lie to what I told myself about my private, subjective intention. Properly understood I never seriously resolved what I thought I had.

Pippin's Hegelian model is in this sense an expressivist account of action. We can and should talk about intentions and actions; such discriminations are themselves partly constitutive of agency. But we must recognize that the inner and outer stand in a dialectically entangled relation. My intention may indeed determine my action, but my actions no less come to determine the meaning, the content of my intentions. But this first complexity immediately leads us to the next one. For on the Hegelian account, this crucial issue about the meaning of my actions inexorably draws others into the story. If I gesture in a busy restaurant to ask for the bill, or transmit what that I take to be a piece of constructive critical feedback to the chef, the meaning of my actions slips beyond my personal control. The very nature of my action, of what I have done, is in significant measure a function of its public reception and interpretation. No amount of pleading about my prior private intention can be decisive in such a dispute. In this way Hegelian agency involves a complex interplay - between inner and outer, public and private, self and other, action and interpretation.

But it also essentially involves reasons and freedom. And here we come to the richest and most original aspects of Pippin's Hegelian position. I cannot possibly hope to do full justice to Pippin's proposals as to the nature of human freedom, so once again I resort to the high altitude sketch, followed by some consideration of its application in a problematic particular case. Let me try to summarize the big picture with four key points. First, Pippin's Hegelian account of human freedom is largely divorced from considerations about causality or causal determination. This by itself is a rather striking departure from the usual range of disputed positions on this topic. Both historically and in the substantial recent scholarship on free agency, the central issues of dispute have revolved around the apparent tension between free will and causal determination, the choice between compatibilist and incompatibilist positions, and so on. Incompatibilists from the Baron d'Holbach through to Galen Strawson hold that freedom requires, impossibly, that the agent be some kind of causa sui.

Compatibilists have advanced an impressive array of proposals about what it is for human behaviour to be caused in the right way so as to constitute free action - choice for Moore, higher-order volitions for 
Frankfurt, the "evaluational system" for Watson, and so on. And Voluntarists from Augustine to Kant try to make sense of some form of quasi-causal determination of action that somehow lies outside the familiar empirical causal chain. But for Pippin's Hegel, all this is essentially barking up the wrong tree. Indeed, in Pippin's boldest formulations, Hegelian freedom has nothing to do with causation. ${ }^{3}$

So if not causality then what? On Pippin's account, the crux of human freedom lies not in an antecedent causal power but rather in an essentially retrospective ability for an agent to recognize her actions as her own. Pippin:

I suggest with Hegel that what we want to be able to explain when we ask 'What is freedom?' are the conditions that must be fulfilled such that my various deeds and projects could be, and could be experienced by me as being, my deeds and projects, as happening at all in some way that reflects and expresses my agency. (36)

It is this basic condition on freedom that Pippin sometimes describes as "the non-alienation condition" - freedom is lost where I experience my own activities as somehow forced upon me, or as effectively channeling the agency of others. (One of Pippin's examples involves a middle manager who is given the task, and the choice, of firing one of two loyal employees.) But this should not be confused with the sort of "negative liberty" construal of freedom, which finds freedom in the absence of constraining interference from others. On Pippin's account, satisfying the non-alienation condition is essentially an accomplishment, something I attain through a complex process of appropriating (owning, if you will) my actions, my choices, and indeed even the circumstances under which I undertake them.

This brings us to the two further crucial components in Pippin's account. Owning my own actions, and in this way recognizing my agency in them, depends crucially on my relation to the reasons for my action. And this in turn is tied up with the social context in which those reasons are adduced. With this we come to the themes of recognition and what Pippin calls "recognitive status" that are explored in the third and final Part of Hegel's Practical Philosophy. I shall not pretend to provide an adequate accounting here - not even a 'high altitude' one. Suffice for now to say this. In order to recognize my action as my own, I must be able to recognize the reasons for my action as my reasons. But at the same time, reasons can only stand in the right sort of relation to my actions insofar as they are genuine reasons, reasons that genuinely justify or make sense of my actions. And once again this is a matter that is simply not within the control of any single individual. What counts as a reason to act in one way rather than another is essentially dependent upon what is recognized, in my community, as a reason. And what makes that communal context something other than a dogmatic imposition is not something that can be spelled out in terms of some final, fully objective set of reasons. For the very notion of a reason, on this account, is linked to the practice of giving and asking for reasons, and such a practice must be historically and socially situated.

\footnotetext{
${ }^{3}$ See, e.g., page 38: "Contrary to most compatibilists, being free does not involve any sort of causality at all." Pippin does not remain entirely faithful to this bold version of the thesis. Characteristically, he presses it as hard and as fully as he can for a couple of hundred pages before finally acknowledging that some sort of causality is indeed involved. (See, e.g., p 190.) This is the (enlightening but maddening) form of Hegelian argument that Pippin describes as "having your cake and eating it too" (273).
} 
Even at this level of generality we can begin to see the intricacy of Pippin's dance with his Relativist and Quietist opponents. Like the Relativist, Pippin locates the business of giving reasons and acting freely upon them essentially in a local, historical context. By their nature, action-justifying reasons cannot transcend such contexts; as we have seen, the very identity of an action depends upon its reception by its contingent local audience. And this in turn seems to commit us to a form of Quietism, since no once-and-for-all philosophical story could settle the matter of what an action means, whether it is justified or free. Philosophy must accordingly surrender its traditional ambitions to replace the local and contingent practices of reason-giving with a universal, objective and necessary form of justification. If this is not to amount to a final surrender to the Relativist and Quietist, then the Hegelian must find an alternate set of ambitions. For Pippin this alternate ambition is decidedly not the business of spelling out some grand, revisionist metaphysics of reality as such. Instead, Pippin's Hegel sets out to construct a history of our reason-giving practices themselves, to account for how we have arrived where we have, with forms of social recognition and practices of justification which can themselves suffice to sustain free rational agency.

All this threatens to become rather too abstract, so by way of conclusion I want to project it back onto my nitty gritty case study: the problem of eating. Consider a young woman suffering from anorexia nervosa - the eating disorder characterized by fear of weight-gain, self-starvation, and distorted body-image. An anorexic makes choices about what to eat (or not to eat) and acts upon those choices, sometimes at the risk of considerable self-harm and even death. Anorexia looks to be a paradigmatic example of pathological agency, a condition that erodes both physical and mental health and fosters deeply irrational, self-destructive behaviour. So how would or could this pathology be described in Pippin's Hegelian categories? Does the anorexic act freely in refusing sustenance? Is her behaviour properly understood as a manifestation of agency at all? And if indeed we want to characterize her condition as pathological, then in what exactly does the pathology consist? How these matters are decided can come to make an enormous difference in practice. If anorexic self-starvation is an expression of rational self-determination then liberal legal regimes characteristically protect it. In the UK, for instance, a competent patient has an absolute right to refuse even life-saving medical interventions. If, on the other hand, it is deemed that the anorexic condition has undermined a patient's agency then the tables are turned: the patient's absolute right is replaced by a set of paternalistic duties-of-care assigned to medical institutions and their staff. Does the Hegelian model provide resources for navigating such cases? I cannot hope to address these matters properly here, but it will be worthwhile to sketch some approaches that are (and are not) available from Pippin's Hegelian position.

From what we have said it should be clear that a Hegelian account of anorexic agency could not turn primarily on the causes of anorexic behaviour. If freedom "does not involve any sort of causality at all" (38), then the question of anorexic freedom would not be settled by discovering, for instance, that anorexic behaviour is caused by some genetic trait or neural trigger, or by some identifiable set of "infected" values. One obvious Hegelian alternative would be to appeal to the nonalienation condition - to a patient's ability to identify with her actions, recognizing her choices as her 
own. But anorexics may seem to pass the non-alienation test all too well. Consider this characteristic report from Participant D in a recent study of anorexic treatment decisions:

I remember getting some tests back saying how my liver was really damaged and all this, and I thought it was really rather good. I can't imagine that I thought it, it felt like really quite an accomplishment ... It's sick, isn't it? It was like somehow I'd achieved! And knowing I almost killed myself; no, I'd say the illness almost killed me, it was like, wow. It was just I'd done something that I knew hardly anyone could do. ${ }^{4}$

Part of what disturbs us here is the patient's identification with a profoundly pathological condition. One might well think that this very identification is robbing the patient of her freedom. But it is not easy to see how such a thought is to be accommodated in an account like Pippin's, which finds the heart of free agency in an agent's ability to identify her actions as her own.

A third alternative would be to follow the lead from Hegelian expressivism. Anorexics characteristically claim that they are fat, even as their body mass index falls to dangerously low levels. They espouse preferences and values that any healthy person would certainly reject. ("I wasn't really bothered about dying, as long as I died thin"5.) If anorexic behaviour is expressive of delusional beliefs and distorted values then this itself would provide the basis for counting the condition as a pathology. But here the question concerns the status of these assessments. Can they be sustained without some form of capitulation to the teleological essentialism of the Ancient Naturalists and their contemporary allies? Both eating and reasoning about eating are activities of organisms (or 'lifeforms') of a particular essential nature. For the Normative Naturalist, the values and beliefs of the anorexic are pathological and delusional precisely because the anorexic's practices of eating have become unhinged from their proper natural function. But this is not a claim that is available to the strict Hegelian, who remains committed above all to the rejection of any "merely given" natural normativity.

We can now see the outlines of a difficulty for Pippin's Hegel. Extrapolate to a community of Hegelian anorexics, each identifying profoundly with their acts of self-starvation, and finding recognition and validation from others in their community. The practice of giving and asking for reasons operates within such a community, and anorexic reasons are recognized as genuine reasons relative to the distinctive values that structure this particular local world. Members of the community risk their lives, to be sure, but they do so in pursuing something that they value above mere biological existence. To round out the Hegelian picture we can add in a reflective apologist, constructing just-so historical narratives that celebrate the anorexic commitment to "break the power of natural inclination" -- finding therein the culmination of mankind's emergence from its merely animal nature. Does the Hegelian have to concede that anorexia has here become a paradigm of modern free agency?

But if Pippin's account creates these sorts of problems for the Hegelian, it should be clear that he also creates opportunities. Consider again the report from Participant D (quoted above). In it we can see much of the texture of agency with which Pippin has taught us to concern ourselves.

\footnotetext{
${ }^{4}$ Participant D, quoted in Tan et al. "Competence to Make Treatment Decisions in Anorexia Nervosa: Thinking Processes and Values" Philosophy, Psychiatry and Philosophy 13:4 (2006), 267-282; see page 276. Participant I in the same study emphasizes how the disease formed "part of my identity".

${ }^{5}$ Patient I, Tan et al. 2006, 274.
} 
Participant D is reflective and retrospective. Although she recalls her earlier identification with her disorder, she has come to externalize it. ("I almost killed myself; no, I'd say the illness almost killed me.”) Notice here the doubly first-personal voice, a characteristic structure of Hegelian agency. The first ' $\mathrm{I}$ ' is that of the remembered participant consciousness; the second that of the remembering and reconstructing phenomenological observer. And of course both voices are here speaking in the distinctive context of the psychiatric interview, in which an agent is invited to externalize (render public) her inner (private) motives and reasons. In all this we find the essential structures of Hegelian agency and freedom: actions and their meanings are essentially extended over time and social space; action is possible only for a being who remembers and reinterprets, and whose reasons can be recognized (and challenged) in an essentially social encounter. Action is thus always at least proleptically political, and freedom can be neither exercised nor assessed synchronically or individually, but only by considering the dynamic, diachronic, intersubjective and recognitional structures in which it is essentially embedded.

Wayne M. Martin University of Essex 